\title{
EDUCAÇÃO E BIBLIOTECAS MULTINÍVEIS: UM OLHAR SOBRE OS DOCUMENTOS NORTEADORES DAS BIBLIOTECAS DA REDE FEDERAL DE EDUCAÇÃO PROFISSIONAL E TECNOLÓGICA EM RONDÔNIA
}

\author{
EDUCATION AND MULTILEVEL LIBRARIES: ANALYSIS OF LIBRARIES GUIDELINES \\ FEDERAL NETWORK OF PROFESSIONAL AND TECHNOLOGICAL EDUCATION IN \\ RONDÔNIA, BRASIL
}

\author{
Miriã Santana Veiga \\ Mestre em Educação \\ Bibliotecária-Documentalista \\ Instituto Federal de Ciência e Tecnologia de Rondônia (IFRO \\ Campus Porto Velho Calama \\ flormiria78@yahoo.com.br \\ Jussara Santos Pimenta \\ Doutora em Educação \\ Professora da Universidade Federal de Rondônia (UNIR) \\ jussara.pimenta@unir.br
}

Recebido em: 08-05-2019

Aceito em: 03-07-2019

\begin{abstract}
Resumo: Este trabalho é resultado de pesquisa realizada no Instituto Federal de Educação, Ciência e Tecnologia de Rondônia (IFRO). Tem como objetivo apresentar conceitos sobre educação, sociedade da informação, letramento informacional, biblioteca escolar e biblioteca multinível e por fim, relacionar esses conceitos com os principais documentos norteadores das bibliotecas do IFRO, que são eles: a Resolução $n^{\circ}$ 21, que trata do Plano de Desenvolvimento de Coleções e a Resolução no 22, que dispõe sobre o Regulamento de Bibliotecas do Instituto. Tratase de uma pesquisa exploratória, bibliográfica e documental. Como resultado foi evidenciado um distanciamento, das resoluções 21 e 22 do real objetivo de uma biblioteca escolar e multinível de se tornarem espaços educativos no que tange ao incentivo a leitura e o letramento informacional. Nos documentos não foram localizadas diretrizes específicas para as funções educativas das bibliotecas e dos bibliotecários, o que distancia as bibliotecas dos eixos norteadores da instituição e da Rede Federal de Educação, Profissional, Científica e Tecnológica (RFEPCT), que busca estimular e apoiar processos educativos que levem à geração de trabalho e renda e à emancipação do cidadão na perspectiva do desenvolvimento socioeconômico local e regional.
\end{abstract}

Palavras-chave: Educação. Biblioteca escolar. Biblioteca multinível. Documentos norteadores. IFRO.

\begin{abstract}
This work is a result of research carried out at the Federal Institute of Education, Science and Technology of Rondônia (IFRO), Brazil. Its purpose is to present concepts about education, information society, information literacy, school libraries and multilevel libraries, and, finally, to relate these concepts to the main guiding documents of IFRO libraries, which are: Resolution 21, which deals with the Collection Development Plan, and Resolution 22, which presents the Institute's Library Regulations. This is an exploratory, bibliographical and documentary research. As a result, there was evidence of withdrawal from the true objective of resolutions 21 and 22 of making school and multilevel libraries educational spaces in terms of encouraging reading and information literacy. Specific guidelines for the educational functions of libraries and librarians were not found in the documents, which distances the libraries from the guiding axes of the Institution and the Federal Network of Professional, Scientific and Technological Education (RFEPCT). This network seeks to stimulate and support educational processes that lead to the generation of work and income and to the emancipation of the citizen from the perspective of local and regional socioeconomic development.
\end{abstract}

Keywords: Education. School library. Multilevel library. Library Guidelines. IFRO. 


\section{INTRODUÇÃO}

A escola é uma instituição social e a educação é um ato cultural. No decorrer da história da humanidade, os atos educativos e formativos sempre fizeram parte das sociedades e ajudou estas a evoluírem e a deixarem legados que até hoje são utilizados pelo homem. Podemos citar, como exemplo, a Sociedade Grega que nos deixou contribuições na Matemática e na Geometria que "foram determinantes e continuam a aplicar-se: o teorema de Pitágoras, a geometria euclidiana e as descobertas geométricas de Tales de Mileto, constituíram uma base fundamental para o desenvolvimento do pensamento matemático" (SIMÕES, 2013, p.01).

De acordo com Carlos Brandão:

Ninguém escapa da educação. Em casa, na rua, na igreja ou na escola, ou de um modo ou de muitos todos nós envolvemos pedaços da vida com ela: para aprender, para ensinar, para aprender-e-ensinar. Para saber, para fazer, para ser ou para conviver, todos os dias misturamos a vida com a educação. (BRANDÃO, 1995, 07p.)

Portanto, o letramento e a alfabetização estão inseridos dentro do universo de formação dos homens e estes estão inseridos no período temporal que está sendo denominado de Sociedade da Informação ou Sociedade do conhecimento.

A expressão "sociedade da informação" passou a ser utilizada, nos últimos anos desse século, como substituto para o conceito complexo de "sociedade pós-industrial" e como forma de transmitir o conteúdo específico do "novo paradigma técnico-econômico". A realidade que os conceitos das ciências sociais procuram expressar refere-se às transformações técnicas, organizacionais e administrativas que têm como "fator-chave" não mais os insumos baratos de energia - como na sociedade industrial - mas os insumos baratos de informação propiciados pelos avanços tecnológicos na microeletrônica e telecomunicações. Esta sociedade pós-industrial ou "informacional”, como prefere Castells, está ligada à expansão e reestruturação do capitalismo desde a década de 80 do século que termina (WERTHEIN, 2000, p.71).

Apresentamos nessa pesquisa, as Bibliotecas Multiníveis do IFRO e as suas relações com as práticas de letramento informacional e a educação. Como base desta análise, escolhemos os dois principais documentos norteadores das bibliotecas do Instituto, que são as resoluções no 21 e 22 . A primeira dispõe sobre o Regulamento de Funcionamento de Bibliotecas do IFRO e a segunda sobre a Política de Desenvolvimento de Coleções.

Questionamo-nos se existe alguma relação dos conceitos sobre Educação, Letramento Informacional, Biblioteca Escolar e Biblioteca Multinível nos principais documentos norteadores e se esses documentos buscam orientar e incentivar a prática educativa nas bibliotecas da instituição e por fim, qual a sua real contribuição aos eixos norteadores da instituição, que são eles: a pesquisa, o ensino e a extensão. Informamos que o IFRO faz parte da Rede Federal de Educação, Profissional, Científica e Tecnológica (RFEPCT), que foi criada e instituída pela Lei n ${ }^{\circ} 11.892$, de 29 de dezembro de 2008. A Lei 11.892 destaca que os Institutos Federais têm como um dos seus principais objetivos “[...] estimular e apoiar processos educativos que levem à geração de trabalho e renda e à emancipação 
do cidadão na perspectiva do desenvolvimento socioeconômico local e regional” (BRASIL, 2008, p. 1, grifo nosso). Ressaltamos também que não seção II da Lei $\mathrm{n}^{\circ} 11.892$, no Artigo Seis, esta Lei destaca sobre a finalidade dos Institutos Federais (IF's) que devem:

I - Ofertar educação profissional e tecnológica, em todos os seus níveis e modalidades, formando e qualificando cidadãos com vistas na atuação profissional nos diversos setores da economia, com ênfase no desenvolvimento socioeconômico local, regional e nacional;

II - Desenvolver a educação profissional e tecnológica como processo educativo e investigativo de geração e adaptação de soluções técnicas e tecnológicas às demandas sociais e peculiaridades regionais;

III - Promover a integração e a verticalização da educação básica à educação profissional e educação superior, otimizando a infraestrutura física, os quadros de pessoal e os recursos de gestão;

IV - Orientar sua oferta formativa em benefício da consolidação e fortalecimento dos arranjos produtivos, sociais e culturais locais, identificados com base no mapeamento das potencialidades de desenvolvimento socioeconômico e cultural no âmbito de atuação do Instituto Federal;

V - Constituir-se em centro de excelência na oferta do ensino de ciências, em geral, e de ciências aplicadas, em particular, estimulando o desenvolvimento de espírito crítico, voltado à investigação empírica;

VI - Qualificar-se como centro de referência no apoio à oferta do ensino de ciências nas instituições públicas de ensino, oferecendo capacitação técnica e atualização pedagógica aos docentes das redes públicas de ensino;

VII - Desenvolver programas de extensão e de divulgação científica e tecnológica;

VIII - Realizar e estimular a pesquisa aplicada, a produção cultural, o empreendedorismo, o cooperativismo e o desenvolvimento científico e tecnológico;

IX - Promover a produção, o desenvolvimento e a transferência de tecnologias sociais, notadamente as voltadas à preservação do meio ambiente (BRASIL, 2008, p. 01).

Sendo assim, as bibliotecas que compõem a Rede Federal (EPCT) têm sua importância elevada, como disseminadoras de informações e deverão ter objetivo primário de auxiliar na formação de cidadãos que deverão criar conhecimentos para si e para as comunidades educacionais em que estão inseridos. Para melhor compreensão, este trabalho está dividido em cinco seções: na primeira seção discutimos os conceitos de educação, sociedade e bibliotecas escolares no Brasil; na segunda apresentamos o IFRO e as suas bibliotecas multiníveis; na terceira apresentamos a metodologia da pesquisa, e por fim, os resultados da pesquisa com a análise dos documentos norteadores das bibliotecas do IFRO e as considerações finais.

\section{EDUCAÇÃO, SOCIEDADE E BIBLIOTECAS ESCOLARES NO BRASIL}

$\mathrm{O}$ ato de viver em sociedade sempre esteve diretamente relacionado a um tipo de educação seja, por meio de observação de práticas manuais, como por exemplo, crianças observando artesãos em ocas de tribos indígenas no Amazonas, ou jovens trabalhando na roça com os pais, todas estão aprendendo e sendo educadas, nestes casos a um trabalho manual. 
Desde seus primórdios a educação sempre foi vista como "formadora do homem", seja do homem da aldeia, do guerreiro, do artesão, do agricultor ou do legislador na Grécia antiga. Todos recebiam "educação" com um único propósito de inserir este homem ao seu "devido lugar", que poderia, por exemplo, ser um servo, administrador ou escribas no Egito antigo.

A educação existe no imaginário das pessoas e na ideologia dos grupos sociais e ali, sempre se espera, de dentro, ou sempre se diz para fora, que a sua missão é transformar sujeitos e mundos em alguma coisa melhor, de acordo com as imagens que se tem uns dos outros (BRANDÃO, 1995, p.12).

Devemos, portanto, entender que a educação jamais deve ser vista como um ato sem interesses políticos ou sociais. Ela está diretamente relacionada com a forma de vida da sociedade e suas ideologias. Nas sociedades primitivas a educação era voltada para a comunidade, para a sobrevivência dos grupos e a criança era educada por todos da comunidade primitiva, está realidade, por exemplo, ainda pode ser observada em aldeias e comunidades africanas.

A educação aparece sempre que surgem formas sociais de condução e controle da aventura de ensinar-e-aprender. O ensino formal é o momento em que a educação se sujeita a pedagogia (a teoria da educação), cria situações próprias para o seu exercício, produz os seus métodos, estabelece suas regras e tempos e constitui executores especializados. (BRANDÃO, 1995, p. 26).

Estes executores especializados, citados por Brandão (1995), são os primeiros mestres, os professores e os formadores da criança. A forma como o ensino acontece hoje na sociedade ocidental, originou-se durante o império romano, que herdou dos gregos a busca pela formação do homem, mas isso obviamente dirigido pelo interesse político, econômico e social. Estas características se mantem até os dias atuais incluídos dentro da educação da Sociedade da Informação, que pode ser excludente e defender apenas as ideias das elites dominantes. Sabemos que a educação não é neutra, é preciso pensar criticamente sobre a escola, a educação e seus processos formativos, como destaca Paulo Freire (1989):

O mito da neutralidade da educação, que leva à negação da natureza política do processo educativo e a tomá-lo como um quefazer puro, em que nos engajamos a serviço da humanidade entendida como uma abstração, é o ponto de partida para compreendermos as diferenças fundamentais entre uma prática ingênua, uma prática "astuta" e outra crítica (FREIRE, 1989, p. 15).

O autor também denota a importância das bibliotecas e da leitura, onde a alfabetização e a formação do educando deverá estar pautada na busca do pensamento crítico da sua própria realidade:

Falar de alfabetização de adultos e de bibliotecas populares é falar, entre muitos outros, do problema da leitura e da escrita. Não da leitura de palavras e de sua escrita em si próprias, como se lê-las e escrevê-las não implicasse uma outra leitura, prévia e concomitante àquela, a leitura da realidade mesma. A compreensão crítica da alfabetização, que envolve a compreensão igualmente crítica da leitura, demanda a compreensão crítica da biblioteca (FREIRE, 1989, p. 15).

No Brasil, um dos setores mais abandonados dentro das escolas são as Bibliotecas Escolares. Isso muitas vezes ocorre por falta de investimento e por faltas de políticas públicas que venham valorizar esses 
espaços de ensino, que são fundamentais para a formação de uma sociedade letrada e que valorizem a leitura. Esse é um dos principais objetivos de uma biblioteca escolar de acordo com Almeida (2015):

Fornecer material informacional necessário às atividades de professores e alunos de uma escola. Deve estar intimamente relacionada com a escola, para funcionar como verdadeiro complemento das atividades realizadas em sala de aula, dando suporte informacional necessário aos processos de ensino-aprendizagem. Desempenha importante papel na formação de leitores e no fomento à prática da leitura. (ALMEIDA, 2015, p. 44).

Em vista disso, nos questionamos. Qual o real papel da biblioteca escolar no Brasil? Será que o número de leitores no país seria tão pequeno, se tivéssemos bibliotecas escolares capacitadas que incentivassem o letramento informacional e o pensamento crítico, que são resultados de hábitos de leitura, e importantes na formação do pensamento científico? De acordo com Gasque (2013), o Letramento Informacional (LI) é um processo de aprendizagem que contribui ao logo da vida do educando.

[...] voltado para o desenvolvimento de competências para buscar e usar a informação na resolução de problemas ou tomada de decisões. O Letramento Informacional é um processo investigativo, que propicia o aprendizado ativo, independente e contextualizado; o pensamento reflexivo e o aprender a aprender ao longo da vida. Pessoas letradas têm capacidade de tomar melhores decisões por saberem selecionar e avaliar as informações e transformá-las em conhecimento aplicável. (GASQUE, 2013, p.01).

A etimologia da palavra Biblioteca tem origem na expressão grega Bibliotheke, que é a junção de duas palavras Biblio que significa livro e tëke, que significa caixa ou depósito, portanto caixa ou armário de livros. Essa última definição representa a realidades das bibliotecas escolares no Brasil, onde as mesmas são verdadeiros depósitos de livros e que nada influenciam na formação do estudante e no seu letramento.

Questionamo-nos também, se a valorização das bibliotecas escolares no Brasil poderia se refletir também na valorização de nossas bibliotecas públicas. Acreditamos que sim, pois são visíveis os diferentes projetos públicos de valorização da cultura e da leitura em países com altos níveis de violência em décadas anteriores. Citemos, por exemplo, as bibliotecas públicas e centros de cultura criados em bairros extremamente violentos da cidade Medelín na Colômbia. As escolas, centros cultuais e as bibliotecas públicas se tornaram centros de valorização daquelas comunidades o que também contribuiu para a diminuição dos abismos sociais e a redução da violência. Os americanos já utilizam essa fórmula em suas bibliotecas públicas desde o início do século XIX. A filosofia de "uma biblioteca pública, menos uma prisão", influenciou as políticas educacionais naquele país.

Como já citado, vivemos na era temporal denominada de Sociedade da Informação, que valoriza a informação como "produto de consumo", em vista disso existe a necessidade que os indivíduos sejam letrados informacionalmente. Um exemplo da necessidade desse letramento ocorre para que os indivíduos analisem criticamente as informações que recebem e que dispõem na sociedade, principalmente por meio das redes sociais, que são acusadas de manipularem os seus públicos e inclusive de causarem tristeza e processos depressivos em seus usuários. De acordo com Jaron Lanier (2018), um dos precursores da realidade virtual, os 
cidadãos devem tomar cuidado com os dados e informações que disponibilizam nas redes sociais, pois as mesmas estão manipulando seus públicos.

Havia um arco moral na história, evidenciado por Martin Luther King, Jr.; a justiça se tornou mais ampla com o passar do tempo. Em determinado período, escravos foram libertados; em outro, mulheres passaram a votar; depois, a população LGBTQ conquistou direitos e respeito. A democracia se espalhou por um número cada vez maior de países. Recentemente, na era Bummer $^{1}$, o arco está mostrando sinais de que vai desmoronar de maneira fragorosa. Não há apenas retrocessos à medida que subimos no arco, mas quedas impensáveis, catastróficas. Nos últimos anos, Turquia, Áustria, Estados Unidos, Índia e outras democracias elegeram líderes de tendência autoritária cujo poder se apoia em tribalismo. Os eleitores estão escolhendo votar contra eles mesmos. Em cada caso, a Bummer exerceu um papel proeminente. Espero, sinceramente, que os nossos tempos sejam lembrados como um pequeno erro de trajeto em uma progressão até então suave para um mundo mais democrático (LANIER, 2018, p.110, grifo nosso).

Portanto, somente o letramento básico não mais influencia na vida dos discentes e futuros cidadãos. Espera-se que os alunos tenham outras habilidades, como explica Luiz Antônio Marcuschi, (2007, p. 32) o “[...] Letramento é uma expressão que hoje vem se especializando para apontar os mais variados modos de apropriação, domínio e uso da escrita como prática social e não como uma simples forma de representação gráfica da língua[...]", pois, o letramento evoluiu com as novas tecnologia da informação e o "[...] Letramento voltou-se para o uso e as práticas e não especificamente para as formas, envolve inclusive todas as formas visuais, como fotos, gráficos, mapas e todo tipo de expressão visual e pictográfica, observável em textos multimodais [...]" (MARCUSCHI, 2007, p. 31).

\section{AS BIBLIOTECAS MULTINÍVEIS DO INSTITUTO FEDERAL DE EDUCAÇÃO, CIÊNCIA E TECNOLOGIA DE RONDÔNIA - IFRO}

O IFRO faz parte do programa de expansão da Rede Federal (EPCT), do Ministério da Educação (MEC). No ano de 2003, existiam no Brasil 140 Escolas Federais de Educação Profissional e essas instituições ofertavam 140 mil novas matrículas em Educação Profissional todos os anos. Atual a rede Federal (EPCT), conta com 354 escolas distribuídas em todo o território nacional.

Os IF estão distribuídos por todo o território brasileiro, funcionam em estrutura multicampi e oferecem cursos de educação básica, profissional e de educação superior (BRASIL, 2008b), tendo basicamente $50 \%$ de suas vagas destinadas a cursos técnicos e $20 \%$ destinadas a cursos superiores (de tecnologia, licenciatura, bacharelado, pós-graduação stricto sensu e lato sensu). Os cursos oferecidos pelos campi procuram adaptar-se às necessidades profissionais, sociais e culturais das regiões onde estão inseridos. (OLIVEIRA; AMARAL, 2012, p.22)

Os Institutos Federais fazem parte de políticas públicas para as regiões em que foram implantados, Oliveira e Amaral (p. 02, 2012) afirma que: “ [...] nesse sentido, as Bibliotecas dos campi dos IF atuam como

\footnotetext{
1 "Behaviors of User Modified, and Made into an Empire for Rent"(BUMMER), expressão criada por Lanier, que em português significa "Comportamentos de Usuários Modificados e Transformados em um Império para Alugar” (LANIER, 2018, p.36).
} 
agentes fundamentais na concretização da missão das instituições, fomentando ensino, pesquisa e extensão, necessitando adequar-se a essa realidade [...]”. No estado de Rondônia o IFRO é uma Autarquia Federal vinculada ao Ministério da Educação (MEC), e foi “criado através da Lei No. 11.892, de 29 de dezembro de 2008, que reorganizou a rede federal de Educação Profissional, Científica e Tecnológica [...]” (IFRO, 2015). Atualmente o IFRO possui nove campi, sendo o mais recente inaugurado o da cidade de Jaru, localizado na região sudeste do Estado de Rondônia.

Um dos setores de destaque de todos os campi do IFRO são as bibliotecas, que ofertam importante suporte informacional a discentes e servidores. As bibliotecas também são os locais que mais recebem visitas da comunidade externa. Em vista da grande variedade de cursos ofertados e das demandas informacionais feita pelos diferentes níveis formativos dos alunos da Rede Feral (EPCT), essas bibliotecas estão sendo denominadas de Bibliotecas Multiníveis. De acordo com Almeida (2015) a Biblioteca Multinível:

[...] é percebida como uma organização que atende aos usuários de diversos níveis de ensino e modalidades educativas. Nesta perspectiva, temos o entendimento de que a biblioteca multinível atenderia, portanto, às necessidades de um público de diferentes níveis de processos formativos (profissionalizante, médio, técnico, superior e pós-graduação) e, consequentemente, diferentes níveis de necessidades e competências informacionais (ALMEIDA, 2015, p.43).

De acordo com último relatório de gestão da Assessoria de Bibliotecas (Abib/IFRO), referente ao ano de 2017, o IFRO possui atualmente 9 (nove) bibliotecas, 14 bibliotecários, 21 auxiliares de biblioteca e dois assistentes administrativos, lotados nas unidades de informação. O sistema gerenciador de acervo que possuem, é o sistema GNUTECA, que é desenvolvido pela empresa Solis, que se localiza, em Lajeado, no Rio Grande do Sul. De acordo com o sistema as bibliotecas possuem atualmente à disposição dos seus usuários 73.189 obras, distribuídas nas áreas de conhecimento determinados pelo Conselho Nacional de Desenvolvimento Científico e Tecnológico (CNPQ), ver Quadro 1.

\begin{tabular}{ccc}
\hline $\mathbf{N}^{\mathbf{0}}$ & ÁREA DE CONHECIMENTO & QUANTIDADE DE EXEMPLARES \\
\hline $\mathbf{0 1}$ & Ciências agrárias & 8121 \\
$\mathbf{0 2}$ & Ciências biológicas & 4596 \\
$\mathbf{0 3}$ & Ciências exatas e da terra & 18615 \\
$\mathbf{0 5}$ & Ciências humanas & 10317 \\
$\mathbf{0 6}$ & Ciências da saúde & 1936 \\
$\mathbf{0 7}$ & Ciências sociais aplicadas & 8377 \\
\hline
\end{tabular}




\begin{tabular}{ccc}
\hline $\mathbf{0 8}$ & Generalidades & 2169 \\
$\mathbf{0 9}$ & Linguística, letra e arte & 13580 \\
$\mathbf{1 0}$ & Área não identificada no Sistema Gnuteca & 400 \\
& Total Geral & $\mathbf{7 3 1 8 9}$ \\
\hline
\end{tabular}

Fonte: Elaborado pelas autoras, com relatório retirado do Sistema GNUTECA, em outubro de 2018.

\section{METODOLOGIA DA PESQUISA}

Este estudo utiliza pesquisa exploratória, onde analisamos documentos que norteiam as atividades das bibliotecas do IFRO, principalmente seu funcionamento e o desenvolvimento de coleções. De acordo, com Prodanov e Freitas (2013, p. 51-52), utiliza-se a pesquisa exploratória:

[...] quando a pesquisa se encontra na fase preliminar, tem como finalidade proporcionar mais informações sobre o assunto que vamos investigar, possibilitando sua definição e seu delineamento, isto é, facilitar a delimitação do tema da pesquisa; orientar a fixação dos objetivos e a formulação das hipóteses ou descobrir um novo tipo de enfoque para o assunto. Assume, em geral, as formas de pesquisas bibliográficas e estudos de caso.

Para a realização do estudo realizamos também, a revisão bibliográfica, que nos ajudou a localizar os conceitos sobre educação, sociedade da informação, letramento informacional, biblioteca escolar e biblioteca multinível e por fim, relacionar esses conceitos com os principais documentos norteadores das bibliotecas do IFRO, que são ele a Resolução $n^{\circ} 21$, que discorre sobre o Plano de Desenvolvimento de Coleções, e a Resolução $\mathrm{n}^{\circ}$ 22, que dispõe sobre o Regulamento de Bibliotecas do IFRO. Ambas foram aprovadas pelo Conselho Superior da Instituição e encontram-se disponíveis nas páginas do IFRO, nos links: Resolução 21 e Resolução 22. Ambos os documentos foram localizados na pesquisa documental.

\section{RESULTADOS E DISCUSSÃO}

Na primeira etapa desta pesquisa, fizemos um levantamento na Resolução número 21, que trata sobre o Regulamento de Funcionamento das Bibliotecas do IFRO e na Resolução no 22 que dispõe sobre a Política de Desenvolvimento de Coleções, dos seguintes termos "Educação", "Práticas educativas", "Informação", "Letramento", "Letramento informacional", "Competência Informacional", "Educador", "competência", "projetos" e "Projetos Educativos". Nosso objetivo foi verificar, se esses termos existiam nos documentos, em seguida iriamos analisá-los, (Ver o quadro 2).

Escolhemos esses termos em vistas das leituras realizadas sobre educação, biblioteca escolar, Letramento Informacional e competência informacional. O Letramento Informacional, de acordo com Gasque (2012, p. 28), é o "processo de desenvolvimento de competências para localizar, selecionar, acessar, organizar, usar informação e gerar conhecimento, visando à tomada de decisão e a resolução de problemas" (grifo 
nosso). Também buscamos o conceito de Competência Informacional que de acordo com Gasque (2013), faz parte do ciclo de aprendizagem do aluno com o uso da informação e seria:

"à capacidade do aprendiz de mobilizar o próprio conhecimento que o ajuda a agir em determinada situação. Ao longo do processo de Letramento Informacional, os aprendizes desenvolvem competências para identificar a necessidade de informação, avaliá-la, buscá-la e usá-la eficaz e eficientemente, considerando os aspectos éticos, legais e econômicos.” (GASQUE, 2013, p.01, grifo nosso)

$\mathrm{Na}$ pesquisa observamos que o termo educação parece apenas uma única vez em cada documento, já o termo informação aparece sete vezes no regulamento e três vezes no plano de desenvolvimento de coleções. Porém, os termos: Práticas educativas; Letramento; Letramento informacional; Competência Informacional; Projetos Educativos e Educador, não aprecem nos documentos (Ver quadro 2).

\begin{tabular}{lccc}
\hline $\mathbf{N}^{\mathbf{0}}$ & Termo & Resolução 21 & Resolução 22 \\
\hline $\mathbf{0 1}$ & Educação & 01 & 01 \\
$\mathbf{0 2}$ & Práticas educativas & 00 & 03 \\
$\mathbf{0 3}$ & Informação & 07 & 00 \\
$\mathbf{0 4}$ & Letramento & 00 & 00 \\
$\mathbf{0 5}$ & Letramento informacional & 00 & 00 \\
$\mathbf{0 6}$ & Competência Informacional & 00 & 00 \\
$\mathbf{0 7}$ & Projetos Educativos & 00 & 00 \\
$\mathbf{0 8}$ & Educador & 00 & 02 \\
\hline $\mathbf{0 9}$ & Competência & 01 & 04 \\
\hline $\mathbf{1 0}$ & Projetos & 02 & \\
\hline
\end{tabular}

Quadro 2- Termos pesquisados nas Resoluções 21 e 22 das Bibliotecas do IFRO

Fonte: Elaborado pelas autoras, 2018.

Os documentos norteadores das bibliotecas do IFRO demonstram que o trabalho educativo do bibliotecário, em documentos oficiais de orientação e gestão de bibliotecas, muitas vezes não ganha destaque e muito menos valorização. Acreditamos que isso pode ser reflexo da formação dos bibliotecários no Brasil, uma vez que a formação, desses profissionais, muitas vezes é direcionada exclusivamente para as práticas biblioteconômicas, como por exemplo, a catalogação, classificação, indexação, administração e marketing, estatísticas, inglês, e outros... Porém, entendemos que os bibliotecários, principalmente os profissionais que atuam em bibliotecas escolares e universitárias, devem receber uma formação voltada para a prática 
educacional. Isso acontece também como uma exigência do planejamento educacional das instituições de ensino.

De acordo com Blattman e Almada (2015):

Nas bibliotecas educacionais é necessário conhecer a proposta pedagógica da instituição, caracterizar o ambiente (efetuar o diagnóstico da instituição) e identificar o perfil do uso e das necessidades da comunidade educacional para estabelecer quais as demandas informacionais e propor serviços e produtos qualitativos na instituição educacional (BLATTMAN, ALMADA, 2015, p. 7).

O país deve buscar inserir na formação de seus profissionais Bibliotecários, uma formação, em que os mesmos, entendam a competência informacional como essencial para a vida dos usuários das bibliotecas. Usuários que estão inseridos na chamada sociedade da informação, é o que orienta, por exemplo, a International Federation of Library Associations and Institutions (IFLA), no documento sobre as "Diretrizes sobre desenvolvimento de habilidades em informação para a aprendizagem permanente":

Os profissionais da informação que atuam em bibliotecas de natureza vária devem ter como um dos seus principais objetivos institucionais a orientação dos usuários para dirigirem seus esforços na aquisição de competências em informação. Estas habilidades são vitais para a aprendizagem permanente, podendo ser utilizadas para a comunicação interpessoal cotidiana de qualquer cidadão, desde uma pessoa que precisa de informação sobre serviços de saúde para alguém a seus cuidados até um estudante que busca encontrar informação específica para completar uma atividade (IFLA, 2007, p. 01).

Se há a necessidade de mudança na formação dos profissionais bibliotecários no Brasil, existe também a mudança das bibliotecas como organizações de ensino/aprendizagem, Concordamos com Almeida, (2015) sobre as mudanças das bibliotecas no Século XXI:

As bibliotecas são cada vez mais desafiadas a transformarem-se em agentes de mudanças no âmbito de sua atuação, não se limitando aos papéis de repositórios de informações e prestadora de serviços, mas são chamadas a adotarem práticas de inovação organizacional que as tornem organizações aprendentes. (ALMEIDA, 2015, p. 18).

Desde seu o início o IFRO investiu em suas bibliotecas, tanto em recursos materiais, quanto em recursos humanos. Atualmente o instituto possui o maior quadro de profissionais bibliotecários e auxiliares de biblioteca contratados no Estado de Rondônia. Nas observações realizadas, na parte inicial deste trabalho, ficou evidente que os eixos norteadores do IFRO e da Rede Feral (EPCT), que são o Ensino, a Pesquisa e a Extensão devem sempre estar entrelaçados para oferecer a melhor formação/educação possível. Esses eixos norteadores devem ficar evidentes nos objetivos, projetos e as atividades das bibliotecas multiníveis do IFRO, pois segundo Blattman e Almada $(2015$, p. 7) “[...] A finalidade da instituição educacional consiste em preparar o educando para interagir na sociedade, contribuindo para o seu desenvolvimento intelectual e pessoal [...]".

Nas Resoluções $n^{\circ} 21$ e n ${ }^{\circ} 22$, observamos o distanciamento de normas e diretrizes para o incentivo do trabalho de educador e o desenvolvimento de práticas educativas realizadas pelos bibliotecários. Porém, observamos por meio dos relatórios localizados das bibliotecas do IFRO, referentes aos anos de 2015 e 2017 , 
que o trabalho dos bibliotecários, não é focado apenas nos processos técnicos biblioteconômicos. Os bibliotecários (as) e suas equipes buscam também ofertar atividades educacionais e formativas aos usuários. Este trabalho, não busca desmerecer os documentos norteadores das bibliotecas do IFRO e nem o trabalho realizado pelas equipes de bibliotecas do IFRO. Nosso objetivo maior é levantar o questionamento sobre as bibliotecas como reais espaços de ensino, mediante o trabalho do bibliotecário.

Questionamo-nos se podemos melhorar nossas bibliotecas com atividades de letramento informacional. Quando observamos todas as ações das bibliotecas do IFRO e sua relação com o processo educacional por meio do letramento informacional, acreditamos que sim, mas precisamos investir nisso, o IFRO e a rede Federal (EPCT), precisa pensar também em suas bibliotecas como espaços formadores.

Por fim, buscamos propor melhorias aos documentos oficiais do IFRO e a debater nos próximos encontros de bibliotecários da instituição, a função das bibliotecas como espaços formadores e o papel do bibliotecário educador no IFRO.

\subsection{UM OLHAR SOBRE OS DOCUMENTOS NORTEADORES DAS BIBLIOTECAS}

Para este trabalho, analisamos primeiramente a Resolução No 21/Consup/Ifro, de 06 de Junho de 2015, que dispõe sobre o Regulamento de Funcionamento de Bibliotecas do IFRO.

No artigo primeiro da Resolução ficam declarados que todos que utilizarem as bibliotecas do IFRO, estão sujeitos ao regulamento. Isso demonstra a abrangência das unidades de informações, que recebem também o público externo a comunidade escolar.

No segundo artigo da Resolução 21, fica destacado que as "[...] As bibliotecas do IFRO têm por finalidade reunir, organizar, divulgar, manter atualizado, preservado e em permanentes condições de uso todo o acervo existente e o que venha a ser incorporado ao patrimônio por aquisição, permuta ou doação [...]"(BRASIL, 2015, p. 5 - grifo nosso). Assim podemos verificar o caráter extremante técnico e exclusivo das unidades que têm sua finalidade direcionada ao acervo.

Os termos como "letramento" ou "educação" não aparecem nessa primeira parte, porém, o terceiro artigo, informa que as bibliotecas são "tecnicamente" responsáveis por "prover” informações. “[...] As bibliotecas do IFRO estão vinculadas à Direção de Ensino e são tecnicamente responsáveis pelo provimento das informações necessárias às atividades de ensino, pesquisa e extensão da Instituição [...]” (BRASIL, 2015, p. 5). Acreditamos que "provimento" de informações, poderá ser alcançando com a aplicação planejada de atividades de letramento informacional.

No capítulo intitulado, "Dos Objetivos" das bibliotecas do IFRO, percebemos novamente o distanciamento das bibliotecas como espaços de formativos, porém, verificamos que as mesmas devem "proporcionar" a "educação de usuários, visando garantir a maximização do uso dos recursos informacionais existentes” (BRASIL, 2015, p. 5). No documento de 22 páginas esta é a única parte em que a palavra Educação aparece. 
I. Reunir, selecionar, processar e disseminar material informacional necessário aos programas de ensino, pesquisa e extensão;

II. Cumprir o papel de depositária da produção intelectual e científica da comunidade do IFRO, que garantam preservar, conhecer e difundir a evolução cultural, artística, científica e histórico-administrativa do IFRO;

III. Proporcionar serviços de comutação, referência e educação de usuários, visando garantir a maximização do uso dos recursos informacionais existentes;

IV. Manter intercâmbio com redes e sistemas de bibliotecas e serviços de documentação e informação, nacionais e internacionais, e participar de cooperação bibliotecária;

V. Interagir com as unidades de ensino, pesquisa, extensão e administração no que diz respeito ao desenvolvimento de atividades que necessitem de sua contribuição;

VI. Interagir com a Direção de Gestão de Tecnologia da Informação visando à otimização dos serviços prestados pela biblioteca;

VII. Coordenar os processos de aquisição de materiais informacionais;

VIII. Disponibilizar aos seus usuários serviços bibliográficos e informacionais;

IX. Propor projetos de interesse a serem desenvolvidos pela biblioteca;

X. Definir política de atualização e desenvolvimento do acervo;

XI. Preservar e conservar seus materiais e equipamentos, desenvolvendo um programa preventivo.

XII. Participar do processo de seleção e aquisição do acervo. (BRASIL, 2015, p. 5 - grifo nosso).

A educação visa a transformação da vida dos usuários/estudantes, e os bibliotecários devem buscar a maximização de recursos informacionais, cujo o objetivo é formar educandos com possibilidades de crescer e se desenvolver educacional e logo culturalmente, buscando assim a sua melhoria de vida.

Na proposta do Letramento Informacional, o comprometimento do bibliotecário com a leitura continua agora em patamar que o leva a assumir responsabilidades não só na escolha de livros e na orientação de leitura, mas no desenvolvimento de habilidades nos alunos para entender e usar competentemente o que leem. Assim, o bibliotecário desempenha a função de orientador nos processos de aprendizagem que privilegiam a busca e uso de informação. Essa função vem se sustentando no conceito de Letramento Informacional (CAMPELLO, 2009, p. 69).

No quinto item, do capítulo "Dos Objetivos" podemos verificar ainda, que o regulamento também abre espaço para que a biblioteca possa interagir com os outros setores da escola, Brasil (2015, p. 6). “[...] Interagir com as unidades de ensino, pesquisa, extensão e administração no que diz respeito ao desenvolvimento de atividades que necessitem de sua contribuição [...]".

No capítulo III “Das estruturas” das bibliotecas do IFRO, verificamos que seus espaços básicos são: o setor de pesquisa, hemeroteca, salas de estudos e outros. Sobre os horários de funcionamento, verificamos que as bibliotecas possuem horários que visa atender todos os turnos abrindo preferencialmente as 07h00min da manhã e fechando às $22 \mathrm{~h} 30 \mathrm{~min}$. 
O acesso às bibliotecas do IFRO é livre ao público e a administração deverá ser feita primariamente pelo bibliotecário: "Art. $8^{\circ} \mathrm{A}$ biblioteca será administrada pelo coordenador, que deverá ser bacharel em Biblioteconomia, em cumprimento à Lei 4.084/62 e ao Decreto Lei 56.725/65” (BRASIL, 2015, p. 6).

No capítulo VI "Das Competências", destaca as funções das Coordenações de Bibliotecas. Primeiramente é competência das Coordenações de Bibliotecas do IFRO, a dinamização e a utilização da biblioteca por toda a comunidade do IFRO, que é formada por docentes, discentes e técnico-administrativos e também, pela comunidade externa. Também cabe à função de planejar e coordenar o treinamento de usuários para garantir o bom funcionamento da biblioteca assim como a integridade do acervo e promover atividades culturais e a elaboração de "atividades, projetos, relatórios, estatísticas e demonstrativas dos serviços executados pela biblioteca" e por fim também cabem às coordenações de bibliotecas do IFRO a realização de "treinamento dos servidores para utilização da biblioteca" (BRASIL, 2015, p.07). Na seção II "Dos Bibliotecários", da Resolução 21, a função educativa dos profissionais, ganha destaque com o objetivo de promover o treinamento de usuários para uso da biblioteca, utilização do sistema de gestão de bibliotecas e uso do portal de periódicos da CAPES, também é função dos bibliotecários a execução de ações de "disseminação da informação e incentivo à leitura [...] Participar da promoção e divulgação da biblioteca junto à comunidade acadêmica" (IFRO,2015, p. 8).

O segundo documento analisado, foi a resolução nº 22 que dispõe sobre a Política de Desenvolvimento de Coleções do IFRO. A Política de Desenvolvimento de Coleções - PDC de uma biblioteca é um documento importante, pois nele são definidos critérios para formação do acervo, é o conjunto de atividades, responsáveis pelo processo de decidir quais obras farão parte do acervo e de que como essas obras poderá impactar o uso do mesmo.

Esta Política de Desenvolvimento de Coleções tem por objetivo possibilitar a formação de coleções de acordo com os objetivos da instituição e a disponibilidade de recursos financeiros, permitindo um processo de seleção sistematizado e consistente, o crescimento racional e equilibrado das diferentes áreas do acervo que deem suporte ao ensino, pesquisa e extensão (BRASIL, 2015, p. 6).

Portanto a PDC das bibliotecas do IFRO está alinhada com os seus eixos norteadores que são o ensino, a pesquisa e a extensão. Na seção 3.1. que trata sobre a formação do acervo observamos que a finalidade do acervo deverá suprir os projetos pedagógicos dos cursos, apoiar os programas de pesquisa e extensão, dar suporte aos serviços administrativos no exercício de suas atividades, fornecer obras de informação que elevem o nível de conhecimento e resguardar materiais importantes que resgatem a história do Instituto. (BRASIL, 2015, p. 10). Não encontramos nenhuma citação sobre educação ou letramento, como palavras destaques dentro do PDC, talvez por ser um manual técnico voltado para a gestão do acervo, embora se faça necessário que as coleções estejam alinhadas com o ensino para que os materiais e ações voltados para a formação dos alunos esteja acessível e completa. No manual não se prevê o uso de uma biblioteca digital do IFRO, o que nos preocupa, pois, o IFRO oferece cursos de Educação a Distância (EaD). Esses alunos estão em diferentes 
municípios do estado de Rondônia e nunca terão a oportunidade de visitar as bibliotecas físicas do IFRO, mas estes poderiam ter acesso às bibliotecas digitais.

Assim como Paulo Freire (1987), acreditamos que "não é no silêncio que os homens se fazem, mas na palavra, no trabalho, na ação-reflexão" e as bibliotecas do IFRO devem acompanhar as mudanças e os paradigmas em que hoje o uso da informação se encontra dentro da Sociedade da informação, com objetivo de atender com qualidade a sua comunidade escolar, seja esta comunidade virtual ou presencial.

\section{CONSIDERAÇÕES FINAIS}

Atualmente o Instituto Federal de Educação, Ciência e Tecnologia de Rondônia- IFRO, possui o maior contingente de profissionais bibliotecários contratados do Estado e é evidente o interesse desses gestores de bibliotecas, por atividades educacionais mediante o uso da informação, porém, isso não se reflete nos documentos norteadores das bibliotecas do IFRO, onde a primazia, nos documentos ocorre pela parte técnica biblioteconômica e administrativa, esquecendo-se completamente do papel educacional e formativos desses espaços. Observamos isso dentro dos dois principais documentos norteadores de duas bibliotecas, a Resolução $n^{\circ} 21$, que trata sobre o Regulamento e Funcionamento de Bibliotecas e a Resolução $n^{\circ} 22$ que dispõe sobre o Plano de Desenvolvimento de Coleções.

Porém, nos documentos, ficou o evidente o distanciamento da biblioteca dos setores pedagógicos e das decisões pedagógicas da escola, o que muitas vezes se torna um sério problema entre as equipes de trabalho e sobre o a real função das bibliotecas multiníveis do IFRO. Portanto, consideramos importante analisar os documentos para se entender em qual estágio as bibliotecas se encontram para, enfim, traçar um plano de ação que vise atender a demanda informacional dos alunos. Sugerimos aqui mais estudos e a elaboração de um Plano de Ação para a melhoria dos serviços informacionais e educacionais para estas bibliotecas multiníveis do Instituto Federal de Educação, Ciência e Tecnologia de Rondônia (IFRO).

\section{REFERÊNCIAS}

ALMEIDA, Jobson Louis Santos. A biblioteca como organização aprendente: o desenvolvimentismo de competências em informação no Instituto Federal de Educação, Ciência e Tecnologia da Paraíba. 2015. 122 f. Dissertação (Mestrado) - Curso de Biblioteconomia, Universidade Federal da Paraíba - UFPB, João Pessoa, 2015.

BRANDÃO, Carlos Rodrigues. O que é educação. 33. ed. São Paulo: Brasiliense, 1995.

BLATTMANN, Ursula; ALMADA, Magda. Biblioteca no ambiente educacional e a sociedade da informação. Disponível em:

https://www.academia.edu/3034276/Biblioteca_no_ambiente_educacional_ea_sociedade_da_informa\%C3\% A7\%C3\%A3o. Acesso em: 23 jul. 2018.

BRASIL. Lei no 11.892 de 29 de dezembro de 2008. Institui a Rede Federal de Educação Profissional, Científica e Tecnológica, cria os Institutos Federais de Educação, Ciência e Tecnologia, e dá outras providências. Diário Oficial [da] República Federativa do Brasil, Brasília, DF, 30 dez. 2008. Disponível em: 
http://pesquisa.in.gov.br/imprensa/jsp/visualiza/index.jsp?jornal=1\&pagina=1\&data=30/12/2008. Acesso em 27 jul. 2018.

BRASIL. Ifro. Ministério da Educação - Mec. RESOLUÇÃO 22: Política de Desenvolvimento de Coleções do Instituto Federal de Educação, Ciência e Tecnologia de Rondônia-IFRO. 2015. Disponível em:

http://www.ifro.edu.br/consup/index.php?option=com_docman\&task=cat_view\&gid=41\&limit=5\&order=na me\&dir=ASC \&Itemid=11\&limitstart=10. Acesso em: 30 jul. 2018.

BRASIL. Ifro. Ministério da Educação - Mec. RESOLUÇÃO 21: Regulamento de Desenvolvimento das bibliotecas do IFRO. 2015. Disponível em:

http://www.ifro.edu.br/consup/index.php?option=com docman\&task=cat view\&gid=41\&limit=5\&order=na me\&dir=ASC\&Itemid=11\&limitstart=10. Acesso em: 06 nov. 2018.

CAMPELlO, Bernadete Santos et al. A biblioteca escolar: temas para uma prática pedagógica. 1.ed. Belo Horizonte: UFMG, 2001.

CAMPELLO, Bernadete Santos. Letramento Informacional no Brasil: práticas educativas de bibliotecários em escolas de Ensino Básico. Tese (doutorado) - Universidade Federal de Minas Gerais, Escola de Ciência da Informação, 2009.

CASTRO, César Augusto. Biblioteca como lugar de memória e eco de conhecimento: um olhar sobre "O Nome da Rosa". Rev. Digital de Biblioteconomia e Ciência da Informação, Campinas, v. 4, n. esp. 2006. Disponível em: http://www.sbu.unicamp.br/seer/ojs/index.php/rbci/article/view/362. Acesso em: 23 nov. 2018.

CERVO, Amado L., BERVIAN, Pedro A., SILVA, Roberto da. Metodologia Científica. 6.ed. São Paulo: Pearson, 2007.

FREIRE, Paulo. A Importância do Ato de Ler: em três artigos que se completam. 22 ed. São Paulo: Cortez, 1989. $80 \mathrm{p}$

GASQUE, Kelley Cristine Gonçalves Dias. Competência em Informação: conceitos, características e desafios. Atoz: Novas práticas em informação e conhecimento, Londrina, v. 2, n. 1, p.5-10, 01 jan. 2013. Semestral. Disponível em: file:///C:/Users/1921139/Downloads/41315-154217-1-PB.pdf. Acesso em: 18 dez. 2018.

IFLA. Diretrizes sobre desenvolvimento de habilidades em informação para a aprendizagem permanente. México: Vera Cruz, 2007, 56 p. Disponível em: https://www.ifla.org/files/assets/informationliteracy/publications/ifla-guidelines-pt.pdf . Acesso em: 01 nov. 2018.

IFRO. Institucional. Porto Velho, 2015. Disponível em: 〈http://www.ifro.edu.br/site/?page_id=9>. Acesso em: 23 jul. 2018.

IFRO. Regimento Geral do IFRO. Porto Velho, 2011. Disponível em: http://www.ifro.edu.br/site/wpcontent/uploads/2009/04/Regimento-Geral.pdf. Acesso em: 24 jul. 2018

MARCUSCHI, Luís Antônio et al. Fala e escrita. Belo Horizonte - Mg: Autêntica, 2007. 208 p.

LANIER, Jaron. Dez argumentos para você deletar suas redes sociais. Rio de Janeiro: Intrínseca, 2018. $145 \mathrm{p}$.

MILANESI, Luis. O que é biblioteca. 8. ed. São Paulo: Brasiliense, 1994. 
MEC. Centenário da Rede Federal de Educação Profissional e Tecnológica. Brasília, 2009. Disponível em: http://portal.mec.gov.br/setec/arquivos/centenario/historico_educacao_profissional.pdf. Acesso em: 23 jul. 2018.

OLIVEIRA, Greissi Gomes; AMARAL, Roniberto Morato do. Mapeamento de processos em bibliotecas: estudo de caso em uma biblioteca do Instituto Federal de Educação, Ciência e Tecnologia de São Paulo. 2012. Disponível em:

http://www.nit.ufscar.br/refbase/PATH_TO_FILES_BASE_DIRECTORY/oliveira/2012/63_Oliveira+Amar al2012.pdf. Acesso em: 18 dez. 2018.

PORTO VELHO. Instituto Federal de Educação Ciência e Tecnologia de Rondônia - IFRO. Relatório geral de atividades da assessoria e coordenação de biblioteca. IFRO. Porto Velho RO: Abib, 2018. 63 p.

PRODANOV, C. C.; FREITAS, E. C. D. Metodologia do trabalho científico: Métodos e Técnicas da Pesquisa e do Trabalho Acadêmico. 2 ${ }^{\mathrm{a}}$. ed. Novo Hamburgo: Universiade Freevale, 2013.

SIMÕES, Susana. A herança grega: O legado político-cultural da civilização grega constitui uma das matrizes da civilização europeia ocidental. 2013. Disponível em:

http://crescendocomhistoria.blogspot.com/2013/10/a-heranca-grega.html. Acesso em: 13 dez. 2018.

WERTHEIN, Jorge. A sociedade da informação e seus desafios. 2000. Revista Ciência da Informação. Disponível em: http://www.scielo.br/pdf/ci/v29n2/a09v29n2.pdf. Acesso em: 10 ago. 2018. 